\title{
Induction of Parthenocarpy in Pointed Gourd (Trichosanthes dioica Roxb.) by Application of Plant Growth Regulators
}

\author{
Jahidul Hassan ${ }^{1 *}$ and Ikuo Miyajima ${ }^{2}$ \\ ${ }^{1}$ Graduate School of Bioresource and Bioenvironmental Sciences, Faculty of Agriculture, Kyushu \\ University, Fukuoka 819-0395, Japan \\ ${ }^{2}$ Institute of Tropical Agriculture, Kyushu University, Fukuoka 819-0395, Japan \\ jhdalim@gmail.com* \\ Tel: 092-802-4832, FAX: 092-802-4850
}

Keywords: Cucurbits, Dioecious, Parthenocarpy, Pointed gourd, Seedless, Trichosanthes dioica

\begin{abstract}
Pointed gourd (Trichosanthes dioica Roxb.) is a dioecious, cucurbit summer vegetable, and green fruit is the main edible part at 15-18 days after pollination. However, consumer preference goes to fruit without seed since seeds are unpalatable to have after cooking due to their hard seed coat. To overcome this problem by parthenocarpy induction, six types of plant growth regulators [2,4-dichlorophenoxyacetic acid (2,4-D); naphthaleneacetic acid (NAA); N-(2-chloro-4 pyridyl)-N'-phenylurea (CPPU); forchlorophenuron (Fulmet); gibberellic acid ( $\left.\mathrm{GA}_{3}\right)$ and 2,3,5triiodobenzoic acid (TIBA) with four concentrations $(25,50,100$ and 200ppm) were sprayed to the unpollinated ovaries of three different female accessions of pointed gourd at anthesis. Results revealed successful parthenocarpy induction by plant growth regulators in all the studied accessions while progressive variation observed in fruit length, diameter and weight according to the differences of plant growth regulators concentrations. The length, diameter and weight of parthenocarpic fruit induced by $\mathrm{GA}_{3}$ at $200 \mathrm{ppm}, \mathrm{CPPU}$ and TIBA at $100 \mathrm{ppm}$ in three studied accessions of pointed gourd were comparable with those of their respective hand-pollinated fruits. In most of the parthenocarpic fruits, seeds were found as empty at ripening stage apart from NAA and $\mathrm{GA}_{3}$ at $200 \mathrm{ppm}$ treated fruits had few abnormal seeds. The results confirmed the useful technique of producing seedless fruits in pointed gourd through the application of GA3 at 200ppm, CPPU and TIBA at 100ppm regardless of accessions.
\end{abstract}

\section{Introduction}

Pointed gourd (Trichosanthes dioica Roxb.), is a dioecious, summer vegetable belongs to the cucurbitaceae family. Young green fruit which is $10-12 \mathrm{~cm}$ length (30-50 g) at 15-18 days after pollination is the main edible size and consumed as vegetable after cooking [1]. However, each fruit contains more than 20 seeds having hard seed coat at 3-4 weeks after pollination while it still remains green in appearance. Even though, this fruit lost consumer acceptance to have it, since seeds are unpalatable due to their hard seed coat. In addition, because of its dioecism, cross pollination is inevitable to fruit set. However, natural pollination leads to poor fruit setting due to its ephemeral flower that deflate 12-14 h after anthesis and asynchronous between male and female flower maturation. Hence, artificial hand pollination is used to improve fruit set, but it is associated with high labor costs.

In this context, parthenocarpic fruit development (i.e. fruit-set and growth without pollination and fertilization) can effectively aid in the resolution of the aforementioned problems. In addition, seedless fruits are desirable for improving the quality of fresh as well as the processed fruit and it has been observed in cucumber, eggplant, watermelon and tomato [2, 3, 4]. Therefore, development of seedless or less seeded fruit is an attractive offer to the consumers. It can be achieved by genetically or chemically induced parthenocarpy. Artificial parthenocarpy involves the stimulation processes same as follow in pollination and fertilization for the growth of a fruit using both natural and synthesized hormones. It resulted in elevated levels of endogenous phytohormones during parthenocarpic fruit set and development from sources other than seeds $[5,6]$. The technology for 
producing seedless fruits based on exogenous plant growth regulators have been successfully applied in cucumber [7, 8], watermelon [9], teasle gourd [10, 11]. Although, parthenocarpy induction in pointed gourd through the use of only NAA (100-500ppm) was firstly noticed by [12]. In that study, they applied NAA before anthesis in T. dioica White Oval type accession and reported maximum parthenocarpic fruit weight of $10.76 \mathrm{~g}$ compared with $16.0 \mathrm{~g}$ of hand pollinated fruits [12]. Besides, in the previous studies the best result on parthenocarpy induction was noticed by the application of not only NAA along with another auxin (2, 4-D), cytokinin (fulmet; CPPU), gibberellin, auxin transport inhibitor (TIBA) at anthesis compared to before and after anthesis. Moreover, the effectiveness of these growth regulators may be depending on the plant species variations, even though genotypic variation of a same species and most importantly the strength of plant growth regulators applied. But, the potential role of diverse plant growth regulators in parthenocarpic fruit set has not been extensively investigated or reported in pointed gourd. Therefore, the present study was carried out to determine the effect of plant growth regulators on inducing parthenocarpy in different pointed gourd accessions.

\section{Materials and Methods}

\subsection{Plant materials}

Mature vines of one male (PGM03) and three female accessions (PGF01, PGF02, and PGF03) of pointed gourd were collected from North-Eastern part of Bangladesh on November 2016 and used for this study. The vines were planted on the soil in a plastic tray and kept on the electricheated hotbed in the glasshouse in Hakozaki campus (lat. $33^{\circ} 37^{\prime} \mathrm{N}$; long. $130^{\circ} 25^{\prime} \mathrm{E}$ ), Kyushu University, Japan. The vines began to sprout on March 2017. The sprouted vines of each accession with 7-10 true leaves were transplanted to the individual plastic pot on first week of April 2017 and maintained in the glasshouse for further growth. Nine individual plants of each accession were used for three replications to ensure the availability of required number of flowers for this study. Five (5) female flowers of each accession were selected to apply each plant growth regulator at different concentrations for one replication and it was replicated for three times. Male plant was maintained in a separate glasshouse to collect pollen for hand pollination with untreated female flowers otherwise all male flowers were discarded to avoid unexpected cross-pollination. The experiment was carried out from April to October 2017.

\subsection{Application of plant growth regulators}

There are six different types of plant growth regulators, specifically, auxins (2, 4-D: 2,4dichlorophenoxyacetic acid and NAA: naphthaleneacetic acid), cytokinins (fulmet: forchlorophenuron and CPPU: N-(2-chloro-4-pyridyl)-N'-phenylurea), gibberellin (GA3: gibberellin $\mathrm{A}_{3}$ ) and auxin transport inhibitor (TIBA: 2,3,5-triiodo benzoic acid) were applied with hand spray to the ovary at anthesis. The ovary of fifteen female flowers for three replications was sprayed to runoff with these plant growth regulators at 25,50,100 and 200ppm $(\mathrm{mg} / \mathrm{L})$ concentrations with Tween $20(0.1 \%)$. The same number of female flowers were sprayed with water and also left for open pollination (unpollinated) that are considered as control treatments. Besides, for hand pollination, pollen was collected from male flowers and pollinated to the stigma of female flowers of each accession at anthesis. All the treated flowers were bagged in the afternoon before anthesis, re-bagged after treatments application and kept covering up to 3-4 days to prevent from open pollination.

\subsection{Data collection}

Fruit set was determined by observing fruit development 5-7 days after the treatment. The length, diameter and weight of the control treatment, hand pollinated and plant growth regulator induced fruit was measured at edible stage. The presence of seeds in all the treated fruits was confirmed after harvest at green stage by vertically bisection. Besides, the seed characteristics of plant growth regulator induced parthenocarpic fruits were also evaluated at ripening stage and compared with the seeds of hand pollinated and control treated fruits. The edible and ripen fruits 
were harvested at 15-18 days and 55-60 days after spray, respectively. The statistical analysis of collected data was performed using R software [13].

\section{Results}

\subsection{Effect of plant growth regulators on fruit set rate}

No fruit set occurred in open pollination (unpollinated flowers) and water treatment but 93.3$100 \%$ fruit set recorded in hand pollination for all the studied accessions (Table 1). According to the current findings, it has been revealed that the effectiveness of concentrations of different plant growth regulators to induce parthenocarpic fruit was increased with the increase of concentration from $25 \mathrm{ppm}$ to $100 \mathrm{ppm}$ and $100 \mathrm{ppm}$ generated the best result. Meanwhile, treatments more than $100 \mathrm{ppm}$ reduced the performance. Such phenomenon was apparent in NAA, fulmet, CPPU, GA3 whereas exception was done in TIBA at 200ppm and 2,4-D at 50ppm. It is generally observed in three studied accessions. The highest percentage of fruit set $(93.3 \%)$ was found in $\mathrm{GA}_{3}$ at 100ppm which was statistically identical with NAA at $100 \mathrm{ppm}$ treatment followed by fulmet $(86.6 \%)$, CPPU $(80.0 \%)$ at $100 \mathrm{ppm}$ and TIBA $(66.6 \%)$ at $200 \mathrm{ppm}$. The lowest fruit set was observed with the treatment of 2,4-D (6.6\%) at 200ppm in PGF01. In case of PGF02 and PGF03 accessions, the consistent effect of these aforementioned plant growth regulators was also noticed to produce maximum and minimum fruit set rate.

Table 1. Effect of different concentrations of plant growth regulators on fruit set rate (\%) of three different pointed gourd accessions

\begin{tabular}{|c|c|c|c|c|}
\hline Treatment $^{\mathrm{z}}$ & Conc. (ppm) & PGF01 & PGF02 & PGF03 \\
\hline Open pollination & & $\mathrm{nf}^{\mathrm{y}}$ & $\mathrm{nf}$ & $\mathrm{nf}$ \\
\hline Hand pollination & & $93.3 \pm 11.5$ & $100.0 \pm 0.0$ & $100.0 \pm 0.0$ \\
\hline Water & & $\mathrm{nf}$ & $\mathrm{nf}$ & $\mathrm{nf}$ \\
\hline \multirow{4}{*}{ 2,4-D } & 25 & $20.0 \pm 20.0$ & $6.6 \pm 11.5$ & $20.0 \pm 0.0$ \\
\hline & 50 & $46.6 \pm 11.5$ & $26.6 \pm 11.5$ & $33.3 \pm 11.5$ \\
\hline & 100 & $13.3 \pm 23.0$ & $26.6 \pm 11.5$ & $13.3 \pm 23.0$ \\
\hline & 200 & $6.6 \pm 11.5$ & $13.3 \pm 11.5$ & $6.6 \pm 11.5$ \\
\hline \multirow{4}{*}{ NAA } & 25 & $26.6 \pm 11.5$ & $26.6 \pm 11.5$ & $20.0 \pm 0.0$ \\
\hline & 50 & $40.0 \pm 20.0$ & $26.6 \pm 11.5$ & $46.6 \pm 23.0$ \\
\hline & 100 & $93.3 \pm 11.5$ & $80.0 \pm 0.0$ & $93.3 \pm 11.5$ \\
\hline & 200 & $46.6 \pm 11.5$ & $40.0 \pm 20.0$ & $40.0 \pm 20.0$ \\
\hline \multirow{4}{*}{ Fulmet } & 25 & $13.3 \pm 11.5$ & $20.0 \pm 0.0$ & $26.6 \pm 11.5$ \\
\hline & 50 & $40.0 \pm 20.0$ & $60.0 \pm 20.0$ & $53.3 \pm 11.5$ \\
\hline & 100 & $86.6 \pm 11.5$ & $100.0 \pm 0.0$ & $100.0 \pm 0.0$ \\
\hline & 200 & $46.6 \pm 23.0$ & $53.3 \pm 11.5$ & $66.6 \pm 11.5$ \\
\hline \multirow{4}{*}{ CPPU } & 25 & $20.0 \pm 20.0$ & $26.6 \pm 11.5$ & $33.3 \pm 11.5$ \\
\hline & 50 & $33.3 \pm 11.5$ & $33.3 \pm 11.5$ & $53.3 \pm 11.5$ \\
\hline & 100 & $80.0 \pm 20.0$ & $100.0 \pm 0.0$ & $93.3 \pm 11.5$ \\
\hline & 200 & $33.3 \pm 11.5$ & $80.0 \pm 0.0$ & $86.6 \pm 11.5$ \\
\hline \multirow{4}{*}{$\mathrm{GA}_{3}$} & 25 & $20.0 \pm 20.0$ & $26.6 \pm 11.5$ & $33.3 \pm 11.5$ \\
\hline & 50 & $33.3 \pm 11.5$ & $33.3 \pm 11.5$ & $46.6 \pm 11.5$ \\
\hline & 100 & $93.3 \pm 11.5$ & $100.0 \pm 0.0$ & $100.0 \pm 0.0$ \\
\hline & 200 & $66.6 \pm 11.5$ & $66.6 \pm 11.5$ & $80.0 \pm 0.0$ \\
\hline \multirow{4}{*}{ TIBA } & 25 & $13.3 \pm 11.5$ & $20.0 \pm 0.0$ & $13.3 \pm 11.5$ \\
\hline & 50 & $26.6 \pm 11.5$ & $33.3 \pm 11.5$ & $53.3 \pm 11.5$ \\
\hline & 100 & $60.0 \pm 0.0$ & $80.0 \pm 20.0$ & $86.6 \pm 11.5$ \\
\hline & 200 & $66.6 \pm 11.5$ & $93.3 \pm 11.5$ & $100.0 \pm 0.5$ \\
\hline
\end{tabular}

Five (5) flowers were used for each treatment and replicated for three times

The data are shown as the mean value \pm standard error

${ }^{z} 2,4-\mathrm{D}=2$, 4,-Dichlorophenoxyacetic acid; NAA = Naphthaleneacetic acid; Fulmet $=$ Forchlorophenuron; CPPU= N-(2chloro- 4-Pyridyl)-N'-phenylurea; $\mathrm{GA}_{3}=$ Gibberellic acid; TIBA=2,3,5-triiodobenzoic acid.

${ }^{\mathrm{y}} \mathrm{nf}$ : no fruit setting. 


\subsection{Effect of plant growth regulators on parthenocarpic fruit characteristics}

$\mathrm{GA}_{3}$ at 200ppm produced longer fruit of $11.2 \mathrm{~cm}$ long and $4.2 \mathrm{~cm}$ diameter followed by TIBA at 100ppm (11.2 cm length and $3.5 \mathrm{~cm}$ diameter) in PGF01 accession and these were closely similar with those of hand pollinated fruit of $13.1 \mathrm{~cm}$ length and $4.4 \mathrm{~cm}$ diameter (Table 2). The larger fruit (51.4 g) was also obtained in PGF01 sprayed with GA3 at 200ppm followed by TIBA (35.3 g) and CPPU (29.4 g) at 100ppm. Similar pattern of results treated with $\mathrm{GA}_{3}$ at 200ppm, TIBA and CPPU at 100ppm were also observed regarding fruit length, fruit diameter and fruit weight in PGF02 and PGF03 accessions.

Table 2. Parthenocarpic fruit characteristics induced by application of different plant growth regulators on three pointed gourd accessions

\begin{tabular}{|c|c|c|c|c|c|c|c|c|c|c|}
\hline \multirow[b]{2}{*}{ Treatments $^{\mathrm{z}}$} & \multirow[b]{2}{*}{$\begin{array}{l}\text { Conc. } \\
\text { (ppm) }\end{array}$} & \multicolumn{3}{|c|}{ PGF01 } & \multicolumn{3}{|c|}{ PGF02 } & \multicolumn{3}{|c|}{ PGF03 } \\
\hline & & $\begin{array}{c}\text { Fruit } \\
\text { length } \\
\text { (cm) }\end{array}$ & $\begin{array}{c}\text { Fruit } \\
\text { diameter } \\
(\mathrm{cm})\end{array}$ & $\begin{array}{c}\text { Fruit } \\
\text { weight } \\
\text { (g) }\end{array}$ & $\begin{array}{c}\text { Fruit } \\
\text { length } \\
\text { (cm) }\end{array}$ & $\begin{array}{c}\text { Fruit } \\
\text { diameter } \\
(\mathrm{cm})\end{array}$ & $\begin{array}{c}\text { Fruit } \\
\text { weight } \\
\text { (g) }\end{array}$ & $\begin{array}{c}\text { Fruit } \\
\text { length } \\
\text { (cm) }\end{array}$ & $\begin{array}{c}\text { Fruit } \\
\text { diameter } \\
(\mathbf{c m})\end{array}$ & $\begin{array}{c}\text { Fruit } \\
\text { weight } \\
\text { (g) }\end{array}$ \\
\hline $\begin{array}{c}\text { Open } \\
\text { pollination }\end{array}$ & & 0 & 0 & 0 & 0 & 0 & 0 & 0 & 0 & 0 \\
\hline $\begin{array}{l}\text { Hand } \\
\text { pollination }\end{array}$ & & 13.1 & 4.4 & 60.5 & 12.0 & 3.9 & 53.4 & 12.6 & 4.0 & 49.4 \\
\hline Water & & 0 & 0 & 0 & 0 & 0 & 0 & 0 & 0 & 0 \\
\hline \multirow{4}{*}{$2,4-\mathrm{D}$} & 25 & 4.1 & 1.1 & 4.0 & 2.3 & 0.7 & 2.0 & 3.7 & 1.2 & 7.2 \\
\hline & 50 & 8.3 & 2.3 & 14.9 & 9.7 & 3.1 & 31.0 & 6.6 & 2.0 & 13.7 \\
\hline & 100 & 1.6 & 0.5 & 1.5 & 5.0 & 1.8 & 4.6 & 0.9 & 0.3 & 0.9 \\
\hline & 200 & 1.4 & 0.3 & 0.7 & 2.2 & 0.7 & 1.0 & 0.8 & 0.2 & 0.5 \\
\hline \multirow{4}{*}{ NAA } & 25 & 6.5 & 1.9 & 6.3 & 6.7 & 2.1 & 9.6 & 5.1 & 1.4 & 3.8 \\
\hline & 50 & 8.1 & 2.2 & 11.0 & 7.1 & 2.0 & 8.8 & 7.4 & 2.0 & 8.8 \\
\hline & 100 & 10.7 & 2.7 & 21.0 & 9.8 & 2.7 & 18.7 & 9.6 & 2.8 & 17.4 \\
\hline & 200 & 8.1 & 2.2 & 13.2 & 7.0 & 2.0 & 8.5 & 6.9 & 1.8 & 8.0 \\
\hline \multirow{4}{*}{ Fulmet } & 25 & 2.7 & 0.9 & 2.1 & 6.3 & 2.1 & 6.3 & 5.3 & 1.4 & 3.1 \\
\hline & 50 & 6.4 & 2.2 & 10.5 & 6.3 & 1.9 & 6.9 & 7.6 & 2.4 & 9.6 \\
\hline & 100 & 9.0 & 3.0 & 24.5 & 9.2 & 3.0 & 21.1 & 9.4 & 3.0 & 18.3 \\
\hline & 200 & 5.9 & 1.7 & 4.5 & 6.2 & 1.8 & 4.8 & 6.4 & 2.1 & 7.4 \\
\hline \multirow{4}{*}{ CPPU } & 25 & 2.3 & 0.9 & 1.7 & 6.5 & 2.1 & 11.5 & 5.2 & 1.4 & 3.6 \\
\hline & 50 & 5.6 & 2.1 & 12.2 & 8.9 & 2.8 & 22.4 & 9.6 & 3.1 & 25.9 \\
\hline & 100 & 8.1 & 3.3 & 29.4 & 11.3 & 3.4 & 40.2 & 10.2 & 3.5 & 39.7 \\
\hline & 200 & 6.1 & 2.2 & 10.1 & 5.5 & 1.8 & 5.4 & 6.7 & 2.3 & 12.0 \\
\hline \multirow{4}{*}{$\mathrm{GA}_{3}$} & 25 & 4.7 & 1.8 & 12.2 & 7.2 & 2.2 & 8.3 & 5.5 & 1.5 & 3.2 \\
\hline & 50 & 8.4 & 2.7 & 19.6 & 8.5 & 2.2 & 9.0 & 7.4 & 2.5 & 11.2 \\
\hline & 100 & 8.4 & 2.8 & 22.2 & 9.0 & 2.7 & 12.8 & 8.5 & 2.7 & 13.6 \\
\hline & 200 & 11.2 & 4.2 & 51.4 & 9.4 & 3.7 & 29.8 & 11.1 & 3.5 & 33.6 \\
\hline \multirow{4}{*}{ TIBA } & 25 & 6.6 & 1.8 & 6.1 & 5.2 & 1.5 & 2.8 & 4.3 & 1.6 & 8.4 \\
\hline & 50 & 9.5 & 3.1 & 26.5 & 8.1 & 2.8 & 18.7 & 9.0 & 2.5 & 22.1 \\
\hline & 100 & 11.2 & 3.5 & 35.3 & 10.9 & 3.4 & 31.2 & 11.8 & 3.5 & 33.8 \\
\hline & 200 & 8.3 & 3.2 & 21.0 & 7.8 & 2.6 & 15.7 & 9.4 & 3.2 & 24.0 \\
\hline Significance & evel ${ }^{y}$ & $*$ & $*$ & $*$ & $*$ & $*$ & $*$ & $*$ & $*$ & $*$ \\
\hline
\end{tabular}

Five (5) flowers were used for each treatment in one replication and the study was replicated for three times.

z2, 4-D = 2, 4,-Dichlorophenoxyacetic acid; NAA = Naphthaleneacetic acid; Fulmet= Forchlorophenuron; CPPU= N-(2chloro-4-Pyridyl)-N'-phenylurea; $\mathrm{GA}_{3}=$ Gibberellic acid; TIBA= 2,3,5-triiodobenzoic acid.

${ }^{\mathrm{y}}$ Mean values represent in each column are significantly different at $\mathrm{P}<0.05$ denoted as *. 


\subsection{Seed characteristics of parthenocarpic and normal seeded fruit}

The application of plant growth regulators to unpollinated flowers of pointed gourd were successfully induced parthenocarpic fruits having lower fruit yield compared to corresponding hand pollinated fruits (Table 3). Surprisingly, these fruits were mostly seedless compare to those of the hand pollinated derived fruits (Fig. 1, Table 3). However, some parthenocarpic fruits induced by NAA and $\mathrm{GA}_{3}$ at 200ppm contained less than 5 seeds which were morphologically seemed abnormal and shorter in size compared to normal seed (Fig. 2B, Table 3). The other plant growth regulators treated parthenocarpic fruits have seed like cavity structure that were empty and covered by thin edible soft layer (Fig. 2C), whereas pollinated ovaries produced several numbers of (23-26) well-developed normal-sized and hard seeds (Fig. 2A, Table 3). Additionally, as there was no fruit formation observed in this present study in case of open pollination (unpollinated) and water treated flowers, therefore, the plant growth regulators induced parthenocarpic fruits were compared with hand pollinated seeded fruits (Fig. 1, 2).
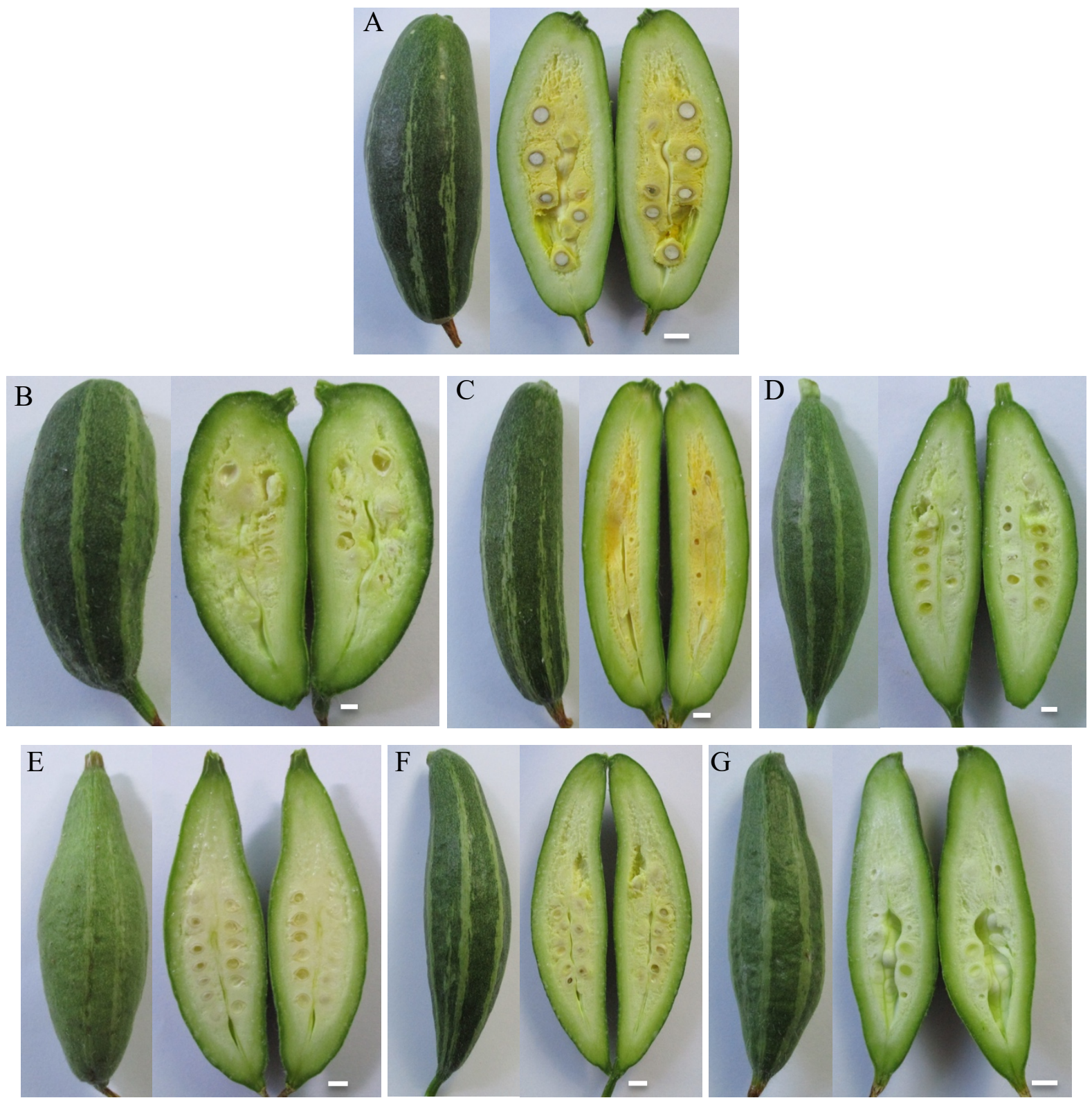

Fig. 1. Fruit characteristics of hand pollinated and parthenocarpic fruits induced by plant growth regulators in pointed gourd at edible stage. (A) Hand pollinated seeded fruit; Parthenocarpic (seedless) fruit induced by (B) 2,4-D, (C) NAA, (D) Fulmet, (E) CPPU, (F) GA3, (G) TIBA. Scale bar, $1 \mathrm{~cm}$ 

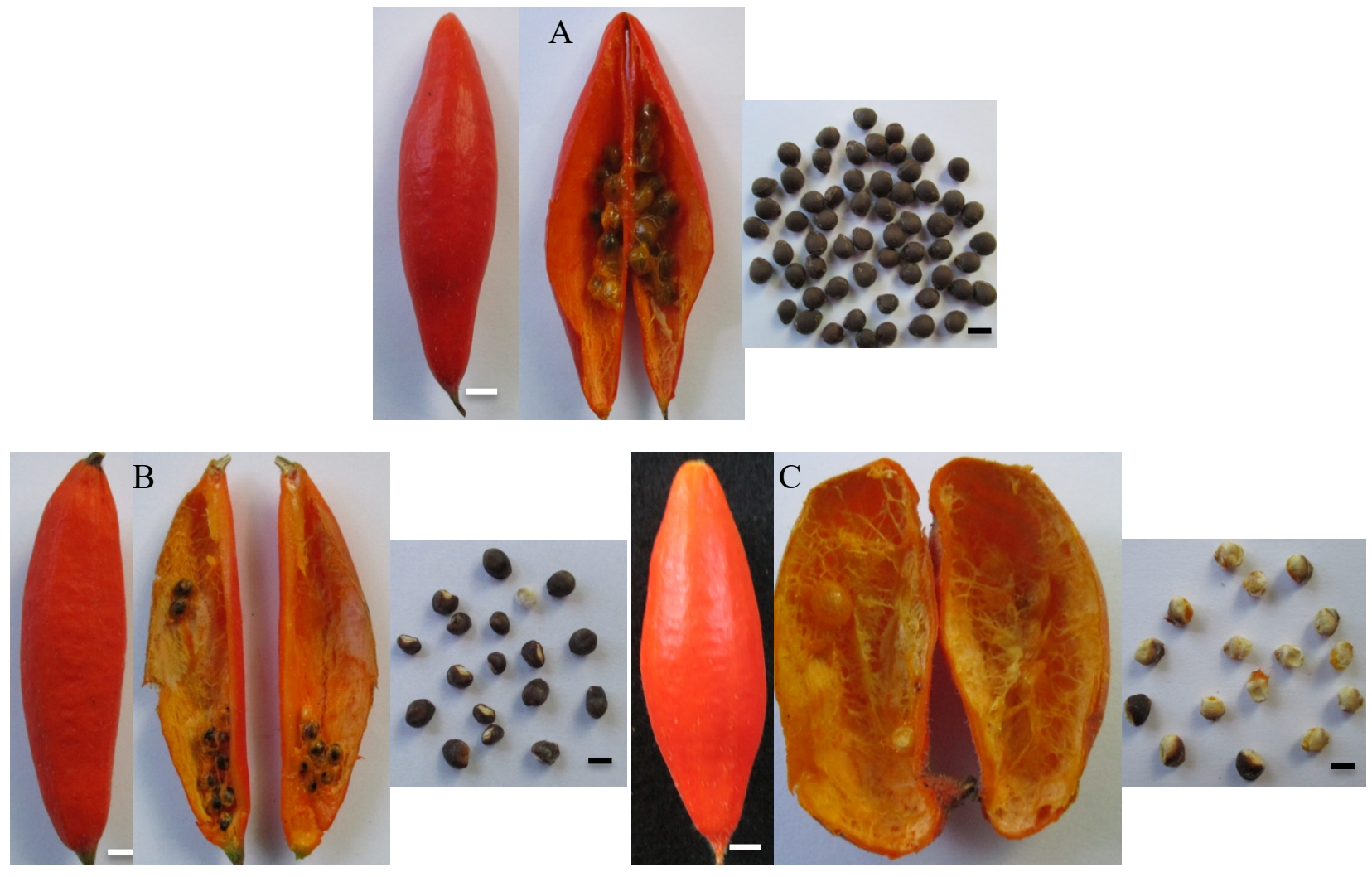

Fig. 2. Fruits and seeds of hand pollinated and parthenocarpic fruits induced by plant growth regulators in pointed gourd at ripening stage. (A) Hand pollinated fruit with normal and viable seeds; (B) NAA at 200ppm induced parthenocarpic fruit with abnormal seeds; (C) GA3 at 200ppm induced parthenocarpic fruit with empty seeds. Scale bar for fruit $1 \mathrm{~cm}$, for seed $5 \mathrm{~mm}$ 
Table 3. Effect of different plant growth regulators on parthenocarpic fruit yield and seed production of three pointed gourd accessions

\begin{tabular}{|c|c|c|c|c|c|c|c|c|c|c|}
\hline \multirow[b]{2}{*}{ Treatments $^{\mathrm{z}}$} & \multirow[b]{2}{*}{$\begin{array}{l}\text { Conc. } \\
\text { (ppm) }\end{array}$} & \multicolumn{3}{|c|}{ PGF01 } & \multicolumn{3}{|c|}{ PGF02 } & \multicolumn{3}{|c|}{ PGF03 } \\
\hline & & $\begin{array}{c}\text { Fruits/ } \\
\text { plant }\end{array}$ & $\begin{array}{l}\text { Fruit } \\
\text { yield } \\
(\mathrm{g})^{\mathrm{x}}\end{array}$ & $\begin{array}{l}\text { Seeds/ } \\
\text { fruit }\end{array}$ & $\begin{array}{c}\text { Fruits/ } \\
\text { plant }\end{array}$ & $\begin{array}{l}\text { Fruit } \\
\text { yield } \\
\text { (g) }\end{array}$ & $\begin{array}{l}\text { Seeds/ } \\
\text { fruit }\end{array}$ & $\begin{array}{c}\text { Fruits/ } \\
\text { plant }\end{array}$ & $\begin{array}{c}\text { Fruit } \\
\text { yield } \\
\text { (g) }\end{array}$ & $\begin{array}{l}\text { Seeds/ } \\
\text { fruit }\end{array}$ \\
\hline $\begin{array}{c}\text { Open } \\
\text { pollination }\end{array}$ & & 0 & 0 & 0 & 0 & 0 & 0 & 0 & 0 & 0 \\
\hline $\begin{array}{l}\text { Hand } \\
\text { pollination }\end{array}$ & & 4.6 & 282.0 & 22.6 & 5.0 & 267.0 & 26.3 & 5.0 & 247.0 & 25.6 \\
\hline Water & & 0 & 0 & 0 & 0 & 0 & 0 & 0 & 0 & 0 \\
\hline \multirow{4}{*}{$2,4-\mathrm{D}$} & 25 & 1.0 & 6.7 & $-w$ & 0.3 & 2.0 & - & 1.0 & 7.2 & - \\
\hline & 50 & 2.3 & 34.9 & - & 1.3 & 45.5 & - & 1.6 & 23.1 & - \\
\hline & 100 & 0.6 & 3.1 & - & 1.3 & 6.2 & - & 0.6 & 1.8 & - \\
\hline & 200 & 0.3 & 0.7 & - & 0.6 & 1.0 & - & 0.3 & 0.5 & - \\
\hline \multirow{4}{*}{ NAA } & 25 & 1.3 & 8.7 & - & 1.3 & 15.0 & - & 1.0 & 3.8 & - \\
\hline & 50 & 2.0 & 21.6 & - & 1.3 & 11.7 & - & 2.3 & 20.3 & - \\
\hline & 100 & 4.6 & 99.6 & - & 4.0 & 75.0 & - & 4.6 & 82.5 & - \\
\hline & 200 & 2.3 & 35.0 & 3.6 & 2.0 & 17.2 & 3.3 & 2.0 & 17.0 & 3.0 \\
\hline \multirow{4}{*}{ Fulmet } & 25 & 0.6 & 2.1 & - & 1.0 & 6.3 & - & 1.3 & 3.9 & - \\
\hline & 50 & 2.0 & 21.3 & - & 3.0 & 22.4 & - & 2.6 & 26.4 & - \\
\hline & 100 & 4.3 & 101.4 & - & 5.0 & 105.6 & - & 5.0 & 91.8 & - \\
\hline & 200 & 2.3 & 10.6 & - & 2.6 & 13.1 & - & 3.3 & 25.4 & - \\
\hline \multirow{4}{*}{ CPPU } & 25 & 1.0 & 2.6 & - & 1.3 & 15.5 & - & 1.6 & 6.1 & - \\
\hline & 50 & 1.6 & 20.3 & - & 1.6 & 37.3 & - & 2.6 & 68.8 & - \\
\hline & 100 & 4.0 & 118.0 & - & 5.0 & 201.1 & - & 4.6 & 185.2 & - \\
\hline & 200 & 1.7 & 16.8 & - & 4.0 & 21.9 & - & 4.3 & 51.9 & - \\
\hline \multirow{4}{*}{$\mathrm{GA}_{3}$} & 25 & 1.0 & 18.3 & - & 1.3 & 10.8 & - & 1.6 & 5.1 & - \\
\hline & 50 & 1.6 & 32.8 & - & 1.6 & 14.9 & - & 2.3 & 26.2 & - \\
\hline & 100 & 4.6 & 103.4 & - & 5.0 & 64.1 & - & 5.0 & 68.1 & - \\
\hline & 200 & 3.3 & 172.4 & 2.6 & 3.3 & 99.2 & 1.6 & 4.0 & 134.6 & 2.3 \\
\hline \multirow{4}{*}{ TIBA } & 25 & 0.6 & 4.3 & - & 1.0 & 2.8 & - & 0.6 & 8.4 & - \\
\hline & 50 & 1.3 & 36.5 & - & 1.6 & 31.1 & - & 2.6 & 59.1 & - \\
\hline & 100 & 3.0 & 105.9 & - & 4.0 & 124.0 & - & 4.3 & 147.6 & - \\
\hline & 200 & 3.3 & 69.2 & - & 4.6 & 73.5 & - & 5.0 & 120.0 & - \\
\hline
\end{tabular}

Significance level ${ }^{\mathrm{y}}$

${ }^{2} 2,4-\mathrm{D}=2,4$,-Dichlorophenoxyacetic acid; NAA = Naphthaleneacetic acid; Fulmet= Forchlorophenuron; CPPU = N-(2chloro-4-Pyridyl)-N'-phenylurea; $\mathrm{GA}_{3}=$ Gibberellic acid; TIBA= 2,3,5-triiodobenzoic acid.

${ }^{\mathrm{y}} \mathrm{Mean}$ values represent in each column are significantly different at $\mathrm{P}<0.05$ denoted as *.

${ }^{x}$ Fruit yield indicates total harvested fruits weight, (Five (5) flowers were used for each treatment in one replication and the study was replicated for three times.)

w_ Seeds absent 


\section{Discussion}

Parthenocarpy was readily induced by various plant growth regulators in all the studied accessions of pointed gourd, but effectiveness was varied with plant accessions and concentrations. Our results depict that parthenocarpic fruit set rate, size (length and diameter) and weight was increased with the increase of NAA, fulmet, CPPU concentration from $25 \mathrm{ppm}$ to $100 \mathrm{ppm}$ afterwards it declined at 200ppm for all the used accessions. On the other hand, this trend of result was followed in $\mathrm{GA}_{3}$ treatment for fruit set rate while fruit size and weight were simultaneously increased with the increase of concentration from $25 \mathrm{ppm}$ to $200 \mathrm{ppm}$. Although, fruit set rate was gradually increased with the increased of TIBA concentration up to $200 \mathrm{ppm}$ but the best fruit size and weight were generated at $100 \mathrm{ppm}$. Moreover, the application of 2,4-D at levels below 50ppm did not result in significant and above it caused phytotoxicity to ovaries resulted in low fruit set, deform fruit shape and degenerated before harvest. Therefore, it can be presumably stated that every plant growth regulator has its own threshold level of action to induce parthenocarpic fruit and above or lower limit of this will not be effective. However, further investigations are required to sort out the regulatory mechanisms associated with parthenocarpic fruit setting in pointed gourd.

Fruit length, fruit diameter and fruit weight are an important factor to be considered in the determination of hormonal concentration for parthenocarpic development of fruits. According to the results, CPPU (100ppm), GA $\mathrm{GA}_{3}(200 \mathrm{ppm})$ and TIBA $(100 \mathrm{ppm})$ were found as the best in parthenocarpic fruit development with considerable length, diameter and weight as compared with seeded fruits. It is generally accepted that fruit setting and associated cell division occur as a result of the coordinated action of phytohormones produced in the ovary after pollination and/or fertilization [14]. [8] proposed that elevated IAA content in the ovary may act as a trigger to induce parthenocarpy and regarded as the major hormonal factor controlling parthenocarpic fruit set.

CPPU was found as more potential in inducing parthenocarpy in our study followed by TIBA, $\mathrm{GA}_{3}$, and auxin had less effect on it (Table 2). However, the optimum CPPU concentration for inducing parthenocarpy differs according to crop species. For instance, CPPU at low concentration $(1 \mathrm{ppm})$ was effective in inducing parthenocarpy in cucumber [8], 10ppm for Chinese whiteflowered gourd [15], but a much higher concentration (200ppm) was necessary for watermelon [9], while $100 \mathrm{ppm}$ effective to produce parthenocarpic fruit with marketable size in our study. The involvement of $\mathrm{GA}_{3}$ and TIBA in inducing parthenocarpy through partially modulation and enhance the biosynthesis of endogenous auxin has already been supported by previous studies. [5] reported that exogenous application of gibberellins augments the auxin level in the ovary of an unpollinated flower to promote cell expansion and other differentiation processes to trigger the fruit setting in absence of fertilization. [16] reported that the application of TIBA to the non-parthenocarpic cucumber fruits doubled their IAA content compared with that of unpollinated ovaries by blocking the natural polar movement of auxin from the ovary resulting in parthenocarpic fruit set in cucumber. Besides, 2,4-D and NAA provided the lowest result in our study, which disputed to the findings of [11] and [12], where 2,4-D and NAA were found the best. [17] claimed that auxin alone is not active for induced pathenocarpy, but combined with gibberellins slightly enhanced the effect of gibberellins on induced parthenocarpy and promotes fruit growth after parthenocarpy. Therefore, 2,4-D and NAA were recognized as less effective than that of others in the present study.

The reduction in induced parthenocarpic fruit weight can be partially explained by the production of less seeds, empty seeds and pseudoembryo treated with plant growth regulators (Table 2, 3; Fig. 1). [18] showed that the final fresh weight of the fruit is positively correlated with the number of seeds per fruit that also affects the final fruit size. Regarding the seed characteristics it has been revealed that the empty seeds in the parthenocarpic fruits were smaller, covered with a soft thin layer and less lignified compared with those in the pollinated fruits (Fig. 2). It might be happened due to the exterior integument had developed as the testa, and pseudoembryo development in the parthenocarpic fruits that act as a substitute for seeds in the control of fruit growth [19]. Consequently, some seeds were found in NAA (200ppm) and GA3 (200ppm) treated fruits, though these seeds were mostly empty, shown abnormal or under-developed. Therefore, it can be said that the external shape of the best-induced parthencarpic fruits by $\mathrm{GA}_{3}$ at $200 \mathrm{ppm}$, CPPU and TIBA at 100ppm was mostly similar to that of pollinated fruits due to having pseudoembryo or seed like empty cavity. 


\section{Conclusion}

From these findings, it can be stated that hand spraying of $\mathrm{GA}_{3}$ at 200ppm, CPPU and TIBA at $100 \mathrm{ppm}$ to the ovary at anthesis may be considered as a useful technique to produce seedless or less seeded pointed gourd fruits irrespective of accession variations.

\section{Acknowledgements}

The authors are sincerely grateful to Bangabandhu Sheikh Mujibur Rahman Agricultural University (BSMRAU), Bangladesh; Material Management Center, Kyushu University, Japan and Plant Protection Station, Ministry of Agriculture, Forestry and Fisheries, Japan for their help and support to collect the plant materials (pointed gourd) for conducting this research in Japan through Material Transfer Agreement (MTA).

\section{References}

[1] T.K. Koley, R. Asrey, D.V.K. Samuel, Effect of sanitizers and storage environment on shelflife and quality of pointed gourd (Trichosanthes dioica). Indian J. Agr. Sci. 79 (2009) 170173.

[2] D.W. Denna, Effects of genetic parthenocarpy and gynoecious flowering habit on fruit production and growth of cucumber (Cucumis sativus L). J. Amer. Soc. Hort. Sci. 98 (1973) 602-604.

[3] F. Varoquaux et al., Less is better: New approaches for seedless fruit production. Trends in Biotechnology. 18 (2000) 233-242.

[4] Z. Yin, The DefH9-iaaM containing construct efficiently induces parthenocarpy in cucumber. Cell Mol Biol Lett. 11 (2006) 279-290.

[5] A.S. Dhatt, G. Kaur, Parthenocarpy: A potential trait to exploit in vegetable crops: A review. Agricultural Reviews. 37(4) (2016) 300-308.

[6] M. Talon, L. Zacarias, M.E. Primo, Gibberellins and parthenocarpic ability in developing ovaries of seedless mandarins. Plant Physiology. 99 (1992) 1575-1581.

[7] G. Elassar et al., Induction of parthenocarpic fruit development in cucumber by growth regulators. Hort. Sci. 9(3) (1974) 238-239.

[8] I.S. Kim, H. Okubo, K. Fujieda, Endogenous levels of IAA in relation to parthenocarpy in cucumber (Cucumis sativus L.). Scientia Hortic. 52 (1992) 1-8.

[9] Y. Hayada, Y. Niimi, N. Iwasaki, Inducting parthenocarpic fruit of watermelon with plant bioregulators. Acta Hortic. 394 (1995) 235-240.

[10] R.N. Chowdhury et al., Effect of plant growth regulators for induction of parthenocarpic fruit in kakrol (Momordica dioica Roxb.). Bangladesh J. Pl. Breed. Genet. 20 (2007) 17-22.

[11] M.G. Rasul et al., Application of plant growth regulators on the parthenocarpic fruit development in teasle gourd (kakrol, Momordica dioica Roxb.). J. Fac. Agr., Kyushu Univ. 53(1) (2008) 39-42.

[12] K.C. Dubey, P.K.R. Nair, Induced parthenocarpic fruit-set in pointed gourd (Trichosanthes dioica Roxb.). Indian Journal of Agricultural Sciences. 42(9) (1972) 765-768.

[13] $\mathrm{R}$ development core team. R: a language and environment for statistical computing. $\mathrm{R}$ foundation for statistical computing, Vienna, Austria. 2010. Available: http:// www.Rproject.org.

[14] B. Gorguet, A.W. van Heusden, P. Lindhout, Parthenocarpic fruit development in tomato. Plant Biology. 7 (2005) 131-139. 
[15] J.Q. Yu, Parthenocarpy induced by N-(2-chloro-4-pyridyl)- N'-phenylurea (CPPU) prevents flower abortion in Chinese white-flowered gourd (Lagenaria leucantha). Env. Exp. Bot. 42 (1999) 121-128.

[16] S. Hikosaka, N. Sugiyama, Effects of exogenous plant growth regulators on yield, fruit growth and concentration of endogenous hormones in gynoecious parthenocarpic cucumber (Cucumis sativus L.). Horticulture Journal. 84(4) (2015) 342-349.

[17] M. Watanabe et al., Effects of plant growth regulators on fruit set and fruit shape of parthenocarpic apple fruits. J. Japan Soc. Hort. Sci. 77(4) (2008) 350-357.

[18] P.C. Groot, J. Bruinsma, C.M. Karssen, The role of endogenous gibberellin in seed and fruit development of tomato: Studies with a gibberellin-deficient mutant. Physiol Plant. 71 (1987) 184-190.

[19] T. Dongping et al., Developmental, chemical and transcriptional characteristics of artificially pollinated and hormone-induced parthenocarpic fruits of Siraitia grosvenorii. RSC Adv. 7 (2017) 12419-12428. 